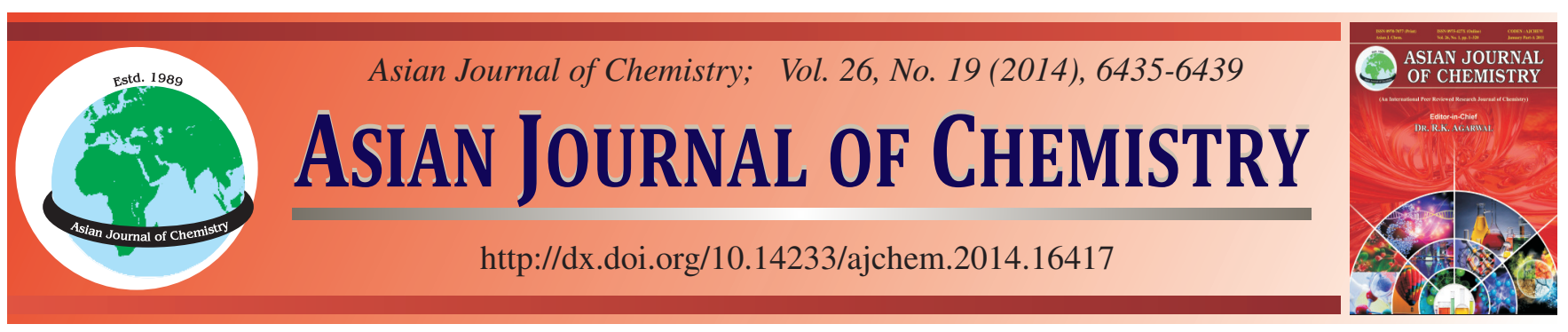

\title{
Conformational Study of Kiwi Fruit (Actinidia chinensis Planch.) Seed Protein Isolates by Fluorescence Spectroscopy
}

Haixia Yang ${ }^{1,2}$, Miaomiao Hu ${ }^{3}$, Daidi Fan ${ }^{3}$, Jinghua Zhang ${ }^{1}$, Jianjun DenG ${ }^{3, *}$ and Ruijuan Zhang ${ }^{1,2, *}$

${ }^{1}$ School of Public Health, Health Science Center, Xi' an Jiaotong University, Xi' an 710061, P.R. China ${ }^{2}$ Nutrition and Food Safety Engineering Research Center of Shaanxi Province, Xi' an 710061, P.R. China

${ }^{3}$ Shaanxi Key laboratory of Degradable Biomedical Materials, Department of Food Science and Engineering, College of Chemical Engineering, Northwest University, Xi' an 710069, P.R. China

*Corresponding authors: Tel/Fax: +86 29 88305118; E-mail: dengjianjun@nwu.edu.cn; zhangrj@mail.xjtu.edu.cn

\begin{abstract}
Kiwi fruit (Actinidia chinensis Planch.) seeds protein isolates (KSPI), a potential source of edible protein, are produced as solid wastes in food industry and remain underutilized yet. Kiwi fruit seed protein isolates had more proteins or peptides with low molecular weights, showing a better digestibility and the proportion of essential amino acids were better than that recommended by FAO/WHO. Fluorescence spectroscopy was used to investigate the conformational changes of KSPI with different environmental conditions including $\mathrm{pH}$ values, temperatures and denaturants. The conformation of KSPI changed significantly at pH 5 and the fluorescence intensity decreased greatly as the temperature increased. The denatured extent of the denaturants was sodium dodecyl sulfate (SDS) $>$ urea $>$ guanidine hydrochloride. These results provide theoretical basis for food manufacturing and indicate that KSPI as a potential ingredient could be used as a substitute for soy protein in food industries.
\end{abstract}

Keywords: Kiwi fruit seed protein isolates (KSPI), Fluorescence spectroscopy, Denaturants, Protein conformation.

\section{INTRODUCTION}

Vegetable/fruit proteins, as a major source of protein nutrition, are widely used in food formulation due to their natural origin. Because of their nutritional value and functional properties, vegetable/fruit proteins are desirable for vegetarian. Soybean, cowpea, cottonseed, peanut and some fruit seeds are the greatest sources of protein meal and represent large amount of the world production ${ }^{1}$. Kiwi fruit (Actinidia chinensis Planch.), also known as the Chinese gooseberry, is the edible berry which is widely produced in the central and southern regions of China. Kiwi fruit seeds, a by-product from kiwi fruit processing, is of high nutritional value because it has been reported to be a rich source of protein, total lipids, crude fiber and polyphenols ${ }^{2}$. However, kiwi fruit seed protein isolates (KSPI), accounting for $150-200 \mathrm{~g} / \mathrm{kg}$ seeds, as the major components of the defatted meal, remains under utilized. Thus KSPI will be a potential excellent food formulation as a nutritional, low-cost and healthy substitute for traditional dairy products for consumers and an ideal functional ingredient supplement for ordinary people.

Conformational changes in proteins are very important as they may affect the nutritional and functional properties of the processed foods ${ }^{3,4}$. Various methods for studying denaturation of food proteins and the role of chemical forces in stabilizing the conformation have been reported ${ }^{5}$. Intrinsic fluorescence spectroscopy is one of the most attractive methods to study the changes in protein conformation under denaturing condition, which involves conformational changes from the native structure due to the disruption of chemical forces that maintain the structural integrity of the protein molecules, such as hydrogen bonds, ionic interactions and covalent disulfide bonds $^{6-8}$. Fluorescence is usually dominated by the contribution of the tryptophan (Trp) residues ${ }^{9}$. Intrinsic fluorescence has been widely used to investigate protein conformation, because the fluorescence characteristics, such as spectrum, quantum yield and quenching, are highly sensitive to the properties of the microenvironment of tryptophan and tyrosine residues in the protein macromolecule and thus can provide a sensitive means of monitoring conformational changes in proteins and protein-protein as well as ligand-protein interactions ${ }^{10}$. Using the fluorescence spectroscopy analysis technique, the conformation changes of some food proteins, such as soybean protein isolates ${ }^{11}$ and kidney bean proteins ${ }^{5}$ has been widely studied.

A better understanding of the characteristics of KSPI especially its conformational and structural properties are very 
important. While KSPI is routinely subjected to loss of proteins' native structure during harvesting, processing and preparation, which in turn can affect their functionality ${ }^{12}$. However, no information is available on KSPI about conformational properties. The objective of this work was to analyze the amino acid composition of KSPI and then mainly investigate the effects of temperature, $\mathrm{pH}$ value, chemical denaturant type and concentration on the conformational properties of KSPI by intrinsic fluorescence spectroscopy to assess the protein conformational and structural changes and can further enhance their potential utilization as a kind of food ingredient.

\section{EXPERIMENTAL}

Dried kiwi fruit seeds were supplied by Qinmei Co., Shaanxi, China. All seeds were collected and stored at $4{ }^{\circ} \mathrm{C}$ until used. All the agents used were of analytical grade and deionized water was used for all the experiments.

Sample preparation: Kiwi fruit seeds were washed in distilled water and air-dried overnight at room temperature. Then, the seeds was ground and defatted for $36 \mathrm{~h}$ with $n$-hexane (seed flour: hexane 1:5, w/v) three times. The defatted seed flour was air-dried at room temperature and ground again to pass through a $0.5 \mathrm{~mm}$ sieve.

Protein extraction: Kiwi fruit seed protein isolates were extracted using the method of Yu et al. ${ }^{13}$, with slight modifications. The defatted kiwi fruit seed flour was dispersed in distilled water $(1: 18, \mathrm{w} / \mathrm{v})$ and the $\mathrm{pH}$ of the dispersion was adjusted to 9 with $1 \mathrm{~mol} / \mathrm{L} \mathrm{NaOH}$. The kiwi fruit seed flour suspension was gently stirred at room temperature for $2 \mathrm{~h}$ and then centrifuged at $12,000 \times \mathrm{g}$ at $4{ }^{\circ} \mathrm{C}$ for $20 \mathrm{~min}$ (Auanti J26XP, Bechman, USA) to separate the insoluble materials. The supernatant was collected and adjusted to $\mathrm{pH} 4.6$ with $1 \mathrm{~mol} / \mathrm{L}$ $\mathrm{HCl}$ and then centrifuged at $10,000 \times \mathrm{g}$ at $4{ }^{\circ} \mathrm{C}$ for $15 \mathrm{~min}$. The obtained precipitate was washed twice by deionized water ( $\mathrm{pH} 4.6)$ and then dissolved in deionized water. The dispersion was homogenized and adjusted to $\mathrm{pH} 7.0$ with $1 \mathrm{~mol} / \mathrm{L} \mathrm{NaOH}$ and centrifuged at $10,000 \times \mathrm{g}$ at $4{ }^{\circ} \mathrm{C}$ for $10 \mathrm{~min}$. The supernatant was dialyzed against deionized water for $48 \mathrm{~h}$ and then freeze-dried to produce KSPI. The protein content was determined according to the micro-Kjeldahl method, using a nitrogen conversion factor of 6.25 .

Sodium dodecyl sulphate-polyacrylamide gel electrophoresis (SDS-PAGE): SDS-PAGE was performed using $12 \%$ acrylamide gel at $12 \mathrm{~mA}$ for $90 \mathrm{~min}$ according to the method of Laemmli ${ }^{14}$. Samples $(20 \mu \mathrm{g})$ were boiled for $5 \mathrm{~min}$ with $25 \%(\mathrm{w} / \mathrm{v})$ glycerol and $2 \%$ SDS in $0.5 \mathrm{M}$ tris $-\mathrm{HCl}, \mathrm{pH}$ 6.8 with $5 \%$ (v/v) $\beta$-mercaptoethanol. Bromophenol blue $(0.01$ $\%, w / v)$ was the tracking dye. Gels were stained with Coomassie Brilliant Blue R-250.

Amino acid analysis: Samples of extracted proteins were hydrolyzed with $2 \mathrm{~mL}$ of $6 \mathrm{~mol} / \mathrm{L} \mathrm{HCl}$ containing $10 \mathrm{mmol} / \mathrm{L}$ phenol and $0.2 \%(\mathrm{v} / \mathrm{v}) \beta$-mercaptoethanol for $20 \mathrm{~h}$ at $110^{\circ} \mathrm{C}$ under a nitrogen atmosphere. After removal of $\mathrm{HCl}$, the amino acid composition was determined using HPLC (Agilent 1100, US). The results are given as $\mathrm{mg} / \mathrm{g}$ of protein.

Intrinsic fluorescence spectroscopy: The fluorescence spectra were performed with a spectrofluorimeter (HITACHI F-4500, Japan) at $25^{\circ} \mathrm{C}$. Kiwi fruit seed protein isolates solutions
$(1 \mathrm{mg} / \mathrm{mL})$ were prepared in $50 \mathrm{mmol} / \mathrm{L}$ phosphate buffer $(\mathrm{pH}$ 7) in the absence or presence of protein perturbants, including sodium dodecyl sulfate (SDS), urea, dithiothreitol (DTT), acrylamide or guanidine hydrochloride $(\mathrm{GdnHCl})$ at different concentrations, respectively. The intrinsic fluorescence emission spectrum was scanned from 290 to $420 \mathrm{~nm}$ at a constant slit of $5 \mathrm{~nm}$ for emission after excitation at $280 \mathrm{~nm}$. Emission spectra of the phosphate buffer were recorded under the same conditions as background spectra.

For experiments involving in preparing different $\mathrm{pH}$ solutions, the $\mathrm{pH}$ values of the solutions were adjusted to the desired values and equilibrated for $1 \mathrm{~h}$. All the protein solutions $(1 \mathrm{mg} / \mathrm{mL})$ were prepared with different $\mathrm{pH}$ and equilibrated for $1 \mathrm{~h}$ prior to the measurements. Three replicates of each sample were measured.

The quenching process of the tryptophan fluorescence was described by the Stern-Volmer equation (eqn. 1$)^{5,15}$. The data on quenching were analyzed according to this equation:

$$
\frac{\mathrm{F}_{0}}{\mathrm{~F}}=1+\mathrm{K}_{\mathrm{SV}}[\mathrm{Q}]
$$

where and are the fluorescence intensities in the absence and presence of quencher, respectively, [Q] is the concentration of the quencher and $\mathrm{K}_{\mathrm{SV}}$ is the Stern-Volmer quenching constant.

The modified Stern-Volmer model (eqn. 2) can be used to analyze quenching data for systems identified to be static quenching:

$$
\frac{\mathrm{F}_{0}}{\mathrm{~F}_{0}-\mathrm{F}}=\frac{1}{\mathrm{~K}_{\mathrm{Q}} \mathrm{f}_{\mathrm{a}}[\mathrm{Q}]}+\frac{1}{\mathrm{f}_{\mathrm{a}}}
$$

where $F, F_{0}$ and [Q] have the same meanings as in eqn. $1, \mathrm{f}_{\mathrm{a}}$ is the fraction of the initial fluorescence that is accessible to the quencher and $\mathrm{K}_{\mathrm{Q}}$ is the effective quenching constant of the exposed tryptophan residues.

Statistical analysis: The data were analyzed using the Statistical Analysis System package software for analysis of variance. Duncan's test. All the experiments were carried out in triplicate.

\section{RESULTS AND DISCUSSION}

The proximate composition of the KSPI, SDS-PAGE was determined and the results were shown in Fig. 1. Lane 1 (control) shows the typical electrophoregram of SSP with major bands of 45-66.2 kDa, $35 \mathrm{kDa}$ and 14.4-25.0 kDa, corresponding to $7 \mathrm{~S}$ and $11 \mathrm{~S}$ soybean protein, which is agreement with earlier report $^{16}$. Kiwi fruit seed protein isolates had 3 major bands which resolved between 66.2-45 kDa, $35 \mathrm{kDa}$ and just below $25 \mathrm{kDa}$ (Lane 2). Compared with SSP, KSPI had less concentrated bands above $14.4 \mathrm{kDa}$. Proteins of KSPI were stacked more on the bromophenol blue band than those of SSP, indicating that KSPI had more small proteins or peptides. Thus, KSPI may represent a better digestibility when it applied as additives in food industries.

The amino acid composition of KSPI was determined and shown in Table-1. Glutamic acid and aspartic acid (the amino acid with negatively charged side chains) were the most abundant amino acid found in the KSPI, making up about 16.20 and $15.40 \%$ of the total amino acid of KSPI, respectively. 




Fig. 1. SDS-PAGE profiles of the KSPI (lane 1) and SSP (lane 2), protein marker standards (lane 3)

Also, KSPI had higher levels of arginine $(7.90 \%)$ and tyrosine $(7.35 \%)$ in comparison to other amino acids. The eight essential amino acids, namely, isoleucine, leucine, lysine, methionine, phenylalanine, threonine, tryptophan and valine, made up approximately $44.65 \%$ of the KSPI. The percentage of some essential amino acids or amino acid pairs of the KSPI in the present study fulfilled or exceeded their respective percentages stated in the 'ideal protein' of WHO (1985). Specifically, isoleucine, methionine + cysteine, phynylalanine + tyrosine and valine of the KSPI were 121, 430, 184 and $171 \%$ of their counterparts stated in the WHO standard, respectively (WHO, 1985). However, the overall quality of the KSPI was slightly compromised by the low level of leucine, lysine and tryptophan, which accounted to only $71.2,74.5$ and $64.5 \%$ of leucine, lysine and tryptophan requirement for children as recommended by FAO/WHO (WHO, 1985) (Table-2).

\begin{tabular}{|c|c|c|}
\hline \multicolumn{3}{|c|}{$\begin{array}{c}\text { TABLE-1 } \\
\text { AMINO ACID COMPOSITION OF KSPI }^{a}\end{array}$} \\
\hline \multirow{2}{*}{ Amino acid } & \multicolumn{2}{|c|}{ Content } \\
\hline & (mg/g dry weight) & (\%) of KSP \\
\hline Aspartic acid (Asp) & 224.1 & 15.40 \\
\hline Serine (Ser) & 50.6 & 3.48 \\
\hline Glutamic acid (Glu) & 235.0 & 16.20 \\
\hline Glycine (Gly) & 59.2 & 4.07 \\
\hline Histidine (His) & 36.7 & 2.52 \\
\hline Threonine (Thr) ${ }^{\mathrm{b}}$ & 47.7 & 3.28 \\
\hline Alanine (Ala) & 95.0 & 6.53 \\
\hline Cystine (Cys) & 11.9 & 0.82 \\
\hline Arginine (Arg) & 115.0 & 7.90 \\
\hline Proline (Pro) & 48.4 & 3.33 \\
\hline Tyrosine (Tyr) & 107.0 & 7.35 \\
\hline Valine $(\text { Val })^{\mathrm{b}}$ & 86.9 & 5.97 \\
\hline Methionine (Met) ${ }^{\mathrm{b}}$ & 37.5 & 2.58 \\
\hline Lysine (Lys) ${ }^{\mathrm{b}}$ & 62.9 & 4.32 \\
\hline Isoleucine (IIe) ${ }^{b}$ & 49.2 & 3.38 \\
\hline Leucine (Leu) ${ }^{\text {b }}$ & 67.4 & 4.63 \\
\hline Phenylalanine (Phe) $)^{\mathrm{b}}$ & 61.9 & 4.25 \\
\hline Proline (Pro) & 48.4 & 3.33 \\
\hline Tryptophan (Try) ${ }^{\mathrm{b}}$ & 10.3 & 0.71 \\
\hline Total & 1455.1 & 100 \\
\hline Essential amino acid & 423.8 & 31.70 \\
\hline
\end{tabular}

${ }^{a}$ The values reported represent the average of three determinations, bssential amino acids.

\begin{tabular}{|c|c|c|c|}
\hline \multicolumn{4}{|c|}{$\begin{array}{c}\text { TABLE-2 } \\
\text { ESSENTIAL AMINO ACID COMPOSITION OF } \\
\text { KSPI COMPARED TO THE WHO IDEAL PROTEIN }\end{array}$} \\
\hline \multirow[b]{2}{*}{ Amino acid } & \multirow{2}{*}{$\begin{array}{l}\text { WHO ideal } \\
\text { protein } \\
\text { (\% of total } \\
\text { protein) }\end{array}$} & \multicolumn{2}{|c|}{ KSPI } \\
\hline & & $\begin{array}{l}(\%) \text { of total } \\
\text { amino acid }\end{array}$ & $\begin{array}{l}(\%) \text { amino } \\
\text { acid/ ideal } \\
\text { protein } \times 100\end{array}$ \\
\hline Isoleucine & 2.8 & 3.38 & 121.0 \\
\hline Leucine & 6.6 & 4.63 & 71.2 \\
\hline Lysine & 5.8 & 4.32 & 74.5 \\
\hline Methionine + cystein & 2.5 & 10.76 & 430.0 \\
\hline Phenylalanine + tyrosine & 6.3 & 11.60 & 184.0 \\
\hline Threonine & 3.4 & 3.28 & 96.5 \\
\hline Tryptophan & 1.1 & 0.71 & 64.5 \\
\hline Valine & 3.5 & 5.97 & 171.0 \\
\hline
\end{tabular}

Effect of pH on conformational properties of KSPI: Fluorescence spectroscopy is a powerful and sensitive technique to characterize $\mathrm{pH}$-induced, temperature-induced and perturbant-induced ambient environment and conformation changes of protein ${ }^{17,18}$. The emission fluorescence spectrum is determined mainly by the polarity of the environment of the tryptophan and tyrosine residues and by their specific interactions, because the fluorescence emission maximum suffers a red shift when chromophores become more exposed to solvent ${ }^{19}$. The tryptophan is an intrinsic fluorophore whose position in the emission maximum $\left(\lambda_{\max }\right)$ depends on the polarity of its microenvironment. The fluorescence intensity and $\lambda_{\max }$ in protein are sensitive to the local environment of fluorophores. At pH $7.0\left(25^{\circ} \mathrm{C}\right)$, KSPI showed a typical intrinsic fluorescence spectrum, with $\lambda_{\max }$ at around $344 \mathrm{~nm}$ (Fig. 2). This is a characteristic fluorescence profile of tryptophan residues in a relatively hydrophilic environment ${ }^{20,21}$.

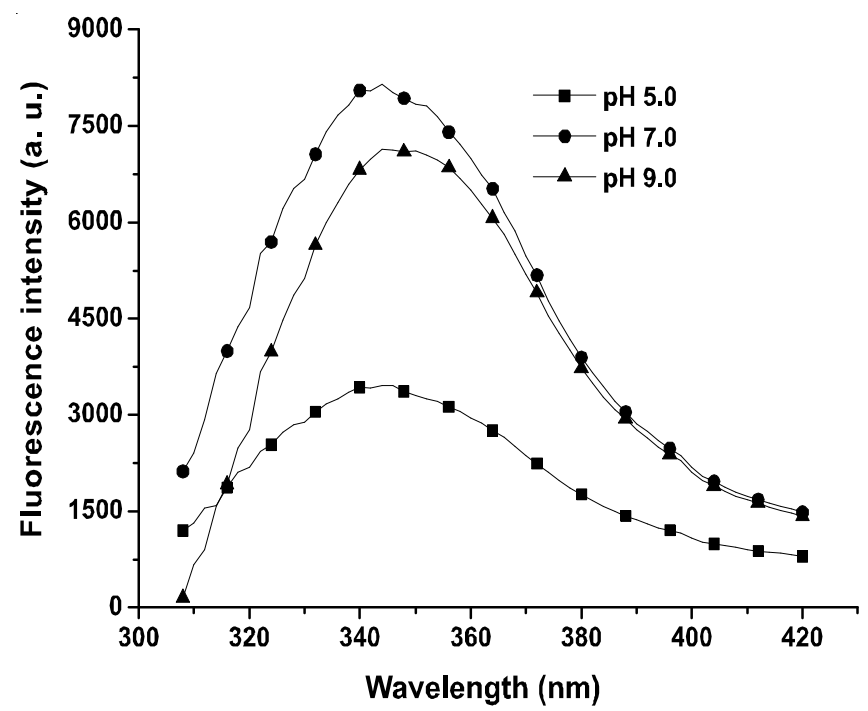

Fig. 2. Fluorescence spectra of KSPI $\left(1 \mathrm{mg} / \mathrm{mL}, 25^{\circ} \mathrm{C}\right)$ at various $\mathrm{pH}$ values. Spectra were recorded using an excitation wavelength of $280 \mathrm{~nm}$

Change in $\mathrm{pH}$ can alter the overall charge on the protein and electrostatic interactions may change protein conformation because of the presence of ionizable amino acids ${ }^{5}$. To determine the effect of $\mathrm{pH}$ on the microenvironment of tryptophan residues in KSPI, the fluorescence spectra were recorded at different $\mathrm{pH}$ values and plotted as a function of $\mathrm{pH}$. Fig. 2 
showed that the $\lambda_{\max }$ suffered a red shift about $3 \mathrm{~nm}$ as the $\mathrm{pH}$ increased from $\mathrm{pH} 5$ to 9 . The red shifts indicated that the polarity around the major tryptophan residue increased. Additionally, the fluorescence intensity decreased greatly when tryptophan residues become less exposed to solvent at $\mathrm{pH} 5$, indicating that the conformational change of KSPI was much more significant at $\mathrm{pH} 5$.

Effect of temperature on conformational properties of KSPI: Proteins suffer a thermodynamically driven process that often leads to denaturation states. Temperature-induced structural changes were also investigated by fluorescence spectroscopy. The $\lambda_{\max }$ of the protein in KSPI had a red shift about $5 \mathrm{~nm}$ as the temperature increased from $25^{\circ}$ to $90^{\circ} \mathrm{C}$ (Fig. 3). This result demonstrated that the polarity of microenvironment of tryptophan residues changed significantly as the temperature changed. In the studied temperature range, the fluorescence intensity decreased with the increase of the temperature, indicating that conformational changes had taken place with most unfolding of the protein, which may result from a protein association induced by its heat denaturation. This fact suggested that the structure of the protein in KSPI is greatly affected by the temperature treatment.



Fig. 3. Fluorescence spectra of KSPI $(1 \mathrm{mg} / \mathrm{mL}, \mathrm{pH}=7)$ at different temperature values. Spectra were recorded using an excitation wavelength of $280 \mathrm{~nm}$

Effect of protein denaturants on conformational properties of KSPI: Chemical denaturation is one of the most widely used methods for the characterization of protein stability because this technique provides access to conformational states that are usually undetectable under native solution conditions ${ }^{22-24}$. Meanwhile, the fluorescence emission spectrum of tryptophan in a protein depends on the type and concentration of denaturant $t^{5,25}$. Fig. 4 shows changes in fractional fluorescence intensity $\left(\mathrm{F}_{0} / \mathrm{F}\right)$ and $\lambda_{\max }$ as a result of protein structure denaturants.

Guanidine hydrochloride, owing to its poor hydration, can interact preferentially with poorly hydrated hydrophobic side chains on a protein's surface and make protein denaturation ${ }^{26}$. The continuous red shifts in emission $\lambda_{\max }$ about $8 \mathrm{~nm}$ were observed up to $4.4 \mathrm{~mol} / \mathrm{L} \mathrm{GdnHCl}$ (Fig. 4a), indicating that tryptophan residues to a more polar environment as a result of the protein denaturation by $\mathrm{GdnHCl}$. When the $\lambda_{\max }$ is over



Fig. 4. Relationships between fractional fluorescence intensity $\left(F_{0} / F\right)$ and emission maximum $\left(\lambda_{\max }\right)$ with the denaturant concentration of $\mathrm{GdnHCl}(\mathrm{a}), \mathrm{SDS}(\mathrm{b})$ and urea (c)

$350 \mathrm{~nm}$ it is an indicative of a relatively hydrophilic environment for the tryptophan residues. This also suggested that there are more tryptophan residues accessible to the aqueous solvent than buried ones as a result of the protein denaturation by $\mathrm{GdnHCl}^{3,27}$. However, with increasing concentration of $\mathrm{GdnHCl}$ exceeding $4.4 \mathrm{~mol} / \mathrm{L}, \lambda_{\max }$ decreased to $344 \mathrm{~nm}$, indicating that higher concentration of $\mathrm{GdnHCl}$ can lead to the tryptophan residues hydrophobic again.

Sodium dodecyl sulfate is an anionic surfactant that commonly used to denature protein but it can also stabilize protein structure. Because the negative charge on the SDS molecules plays a crucial role in leading to protein denaturation, it has a strong effect on the folding/unfolding transitions in protein and the effect is concentration dependent ${ }^{28}$. The fluorescence spectrum at different concentrations showed that low concen- 
tration at $\mathrm{SDS}<3 \mathrm{mM}$ could largely cause the change of protein structure (Fig. 3b). After this, it is observed that tryptophan fluorescence intensity increased slowly with the increasing SDS concentration. The increased fluorescence intensity might be attributed to the SDS-induced dissociation of protein aggregates in $\mathrm{KSPI}^{5}$. At the same time, a significant blue shift in $\lambda_{\max }$ of KSPI from 344 to $334 \mathrm{~nm}$ was recorded at $\mathrm{SDS}<3$ $\mathrm{mmol} / \mathrm{L}$. It may due to a SDS-induced change of hydrophobic microenvironment surrounding the tryptophan residues.

Urea, as a widely used protein denaturant, can make protein unfolded without significantly altering the microenvironment of tryptophan residues of the protein ${ }^{29}$. Fig. $3 c$ showed that the increased urea enhanced the fluorescence intensity but no changes in $\lambda_{\max }$ were found at increasing concentration of urea. The mechanism may be because urea can penetrate to the interior of the protein because of its high solubility in aqueous solution and small size. Therefore, an increased effective volume of the protein due to swelling with the increasing urea concentration generates a cooperative effect for protein denaturation $^{30}$.

\section{Conclusion}

In this work, fluorescence properties for KSPI have been systematically investigated by using three kinds of denaturant ( $\mathrm{SDS}, \mathrm{GdnHCl}$ and urea) with different temperatures and $\mathrm{pH}$. SDS-PAGE results showed that KSPI had more small proteins or peptides with molecular weight, indicating a better digestibility. Amino acid composition indicated that the proportion of essential amino acids were better than that recommended by FAO/WHO. Fluorescence spectrum results showed that SDS caused blue shifts in the $\lambda_{\max }$ from 344 to $334 \mathrm{~nm}$ and increased fluorescence intensity of tryptophan residues significantly. However, increasing $\mathrm{GdnHCl}$ resulted in a red shift of $\lambda_{\max }$ from 344 to $352 \mathrm{~nm}$, indicating a relatively hydrophilic environment for the tryptophan in KSPI. It provides theoretical basis for food manufacturing and could be used as a substitute for soy protein in food industries. We will focus on the functional properties of KSPI in further study.

\section{ACKNOWLEDGEMENTS}

This project was supported by the National Natural Science Foundation of China (21306146), China Postdoctoral Science Foundation funded project (2013M532055, 2014T70926), the Shaanxi Provincial Scientific Technology Research and
Development Program (2012JQ2019) and Specialized Research Fund for the Doctoral Program of Higher Education of China (20130201120077).

\section{REFERENCES}

1. V.R. Young and P.L. Pellett, Am. J. Clin. Nutr., 59, 1203S (1994).

2. M. Lísa, M. Holcapek and M. Bohác, J. Agric. Food Chem., 57, 6888 (2009).

3. K.K. Turoverov and I.M. Kuznetsova, J. Fluoresc., 13, 41 (2003).

4. E.C.Y. Li-Chan, Adv. Exp. Med. Biol., 434, 5 (1998).

5. S.W. Yin, C.H. Tang, X.Q. Yang and Q.B. Wen, J. Agric. Food Chem., 59, 241 (2011).

6. K. Chattopadhyay, S. Saffarian, E.L. Elson and C. Frieden, Biophys. J., 88, 1413 (2005).

7. G.P. Gorbenko, J. Fluoresc., 21, 945 (2011).

8. C.Y. Ma and V.R. Harwalkar, J. Food Sci., 53, 531 (1988).

9. J. Domenech, J.M. Nieto and J. Ferrer, J. Mol. Catal. B, 61, 168 (2009).

10. I. Pallarès, J. Vendrell, F.X. Avilés and S. Ventura, J. Mol. Biol., 342, 321 (2004).

11. A.P. Batista, C.A. Portugal, I. Sousa, J.G. Crespo and A. Raymundo, Int. J. Biol. Macromol., 36, 135 (2005).

12. J.E. Kinsella and N. Melachouris, Crit. Rev. Food Sci. Nutr., 7, 219 (1976).

13. J. Yu, M. Ahmedna and I. Goktepe, Food Chem., 103, 121 (2007).

14. U.K. Laemmli, Nature, 227, 680 (1970).

15. Y. Zhang, Z.D. Qi, D. Zheng, C.H. Li and Y. Liu, Biol. Trace Elem. Res., 130, 172 (2009).

16. M. Zhang, J. Gao and H. Yang, Cereal Chem., 86, 261 (2009).

17. J.M. Sanchez-Ruiz, Subcell. Biochem., 24, 133 (1995).

18. G.E. Plum and K.J. Breslauer, Curr. Opin. Struct. Biol., 5, 682 (1995).

19. M.C. Stumpe and H. Grubmuller, J. Am. Chem. Soc., 129, 16126 (2007).

20. E. Dufour, G.H. Hoa and T. Haertlé, Biochim. Biophys. Acta, 1206, 166 (1994).

21. I. Pallarés, J. Vendrell, F.X. Avilés and S. Ventura, J. Mol. Biol., 342, 321 (2004).

22. E.J. Guinn, L.M. Pegram, M.W. Capp, M.N. Pollock and M.T. Record, Proc. Natl. Acad. Sci. USA, 108, 16932 (2011).

23. C.N. Pace, Methods Enzymol., 131, 266 (1986).

24. J.A. Schellman, Biopolymers, 26, 549 (1987).

25. S.M. West, A.D. Guise and J.B. Chaudhuri, I Chem. E., 75, 53 (1997).

26. P.E. Mason, G.W. Neilson, C.E. Dempsey, A.C. Barnes and J.M. Cruickshank, Proc. Natl. Acad. Sci. USA, 100, 4557 (2003).

27. K.K. Turoverov, V.V. Verkhusha, M.M. Shavlovsky, A.G. Biktashev, O.I. Povarova and I.M. Kuznetsova, Biochemistry, 41, 1014 (2002).

28. S.D. Arntfield, E.D. Murray and M.A.H. Ismond, J. Agric. Food Chem., 38, 1335 (1990).

29. A. Das and C. Mukhopadhyay, J. Phys. Chem. B, 112, 7903 (2008).

30. H.A. Scheraga and L. Mandelkern, J. Am. Chem. Soc., 75, 179 (1953). 